\title{
Integration of Future Maintenance Actions in the Prediction of the Parameters of the ATLAS COPCO ZR 200 Compressor
}

\author{
Agnès Virginie Tjahè ${ }^{1}$, Blaise Mtopi Fotso ${ }^{2}$, Médard Fogué ${ }^{3}$, and Noureddine Zerhouni ${ }^{4}$ \\ 1,2,3 Industrial Systems and Environmental Engineering Research Unit (UR-ISIE), Fotso Victor Institute of Technology of \\ Bandjoun, University of Dschang, PO Box 134, Bandjoun, Cameroon \\ 1,2,3 Department of Mechanical Engineering and Computed Integrated Manufacturing, Fotso Victor Institute of Technology of \\ Bandjoun, University of Dschang, Cameroon \\ agnes.tjahe@univ-dschang.org
}

${ }^{4}$ FEMTO-ST, University of Bourgogne-Franche-Comté, 15B avenue des Montboucons, 25030 Besançon CEDEX, France

\begin{abstract}
The prediction of several failure modes of an industrial equipment requires the development of prediction systems with several interdependent parameters. The integration of future maintenance actions with this type of prediction system is a major asset for maintenance decision making. This is even more relevant in the event that after having predicted the future occurrence of several failure modes, the maintenance department does not have the necessary resources to correct all the predicted failure modes at once. In this case it becomes necessary to know how much longer the equipment will work if future partial maintenance actions that do not correct all failure modes are implemented. It is to contribute to the resolution of this problem that we propose an architecture integrating the future maintenance actions to the prediction of several interdependent parameters. This architecture is based on the association of Proportional Integral Derivative regulators to Neuro-Fuzzy systems taking into account the four previous instants to predict the next instant. An application is made with accuracies of the order of $70 \%$ for the prediction of the phenomena of fouling of the coolers and of the order of $90 \%$ for the prediction of the phenomena of clogging of the filters of the ATLAS COPCO compressor, this with Central Processing Unit values not exceeding one minute.
\end{abstract}

Agnès Virginie Tjahè et al. This is an open-access article distributed under the terms of the Creative Commons Attribution 3.0 United States License, which permits unrestricted use, distribution, and reproduction in any medium, provided the original author and source are credited.

https://doi.org/10.36001/IJPHM.2021.v12i2.2916

\section{INTRODUCTION}

Improving availability has established itself as one of the major challenges for industrial companies of our time (Elasha, Shanbr, Li, and Mba, 2019). The anticipation of failures (preventive maintenance), now at the heart of the maintenance activity allows a real improvement in the availability and reliability of systems (Sammouri, 2014; Soualhi, Nguyen, Soualhi, Medjaher, and Hemsas, 2019). Therefore, it is necessary for the industrialists to predict the ideal moment to intervene. This is known as the prognostic process (Daher, Hoblos, Khalil, and Chetouani, 2020). The industrial prognosis is based on the prediction of the evolution of the degradation of components according to past commitments but also future solicitations (Lemaitre González, 2019).

In the field of industrial prognosis, several approaches have been implemented, the data-driven approach is widely used. Data-driven prognostic methods aim at transforming raw monitoring data into relevant information and behavior models (including the degradation) of the system. They take as inputs the current monitoring data and return as outputs predictions or trends about the health state of the system (Gouriveau \& Medjaher, 2011). In terms of the failure prognosis via the data-driven approach, several mutations have been observed. We started with the use of Neural Networks (NN), at the looped NN of Zemouri (2003). To improve accuracy, Zemouri, Gouriveau, and Patic (2010) associate a PID (Proportional Integral Derivative) controller with the looped NN. These PID controllers have several parameters at different horizons of prediction, which seems tedious. 
Today, data-driven prognostic is based on hybrid systems such as Neuro-Fuzzy networks and the most widely used in the literature is the Adaptive Neuro-Fuzzy Inference System (ANFIS) proposed by Jang (1993). The ANFIS model is still widely used in recent works. For example, Soualhi et al. (2019), Soualhi, Medjaher, Celrc, and Razik (2020) and Motahari-Nezhad and Jafari (2020) have shown that the ANFIS model is suitable for short-term prediction of bearing failures. Sparthan, Nzie, Soh Fotsing, Beda, and Garro (2020) also obtained satisfactory results when implementing several ANFIS models for the prediction of failures in a track breaking system. Daher et al. (2020) propose the combination of several ANFIS models in a new prognostic approach applied to a distillation column.

Most of the ANFIS-type systems developed in the literature relate for some to the reduction of the prediction error, and for others to the control of this error (Dragomir, Dragomir, Stefan, and Minca, 2015; Wang, Hong, Chen, and Tang, 2015; Auand \& Priyanka, 2016; Syahputra, 2016; Zhuang, Yu, Sun, and Song, 2021). However, these works reveal the need to develop efficient and low-complexity prediction systems for the prediction of several parameters. Such prediction systems would be closer to the requirements of real industrial systems. It is in line with these requirements and inspired by the work of Jang, Suni, and Mizutani (1997) that the work of Tjahe, Mtopi Fotso, Djanna, and Fogue (2017a) led to the proposal of an uncomplicated MANFIS (Multioutputs Adaptive Neuro-Fuzzy System) for the efficient prediction of three interdependent parameters. To improve the prediction performance of this system, Tjahe, Mtopi Fotso, Djanna, and Fogue (2017b) combines constant parameter PID controllers with a MANFIS subsystem for the control of prediction error. The resulting MANFIS-PID system allows for a decrease in prediction error without increasing the complexity of the prediction algorithm.

Besides the need to develop low-complexity, highperformance prediction systems dedicated to the prediction of several parameters, it is necessary to integrate Future Maintenance Actions (FMA) into the prediction (Dragomir, 2008; Adeline, Gouriveau, and Zerhouni, 2008). For this reason, Dragomir (2008) proposed a system that integrates future maintenance actions with the prediction of a single parameter. Considering that most industrial equipment have several parameters that are interdependent, and that are characteristic of several failure modes, it would be interesting to integrate the Future Maintenance Actions to the prediction of several parameters. This taking into account that, a partial FMA may not restore all the parameters of the industrial equipment to their ideal values. This eventuality is very frequent in the event that all the conditions and all the resources (material, human, etc.) are not gathered to totally remedy the failure.
One of the most commonly used rotating equipment in industrial companies is the compressor for the production of compressed air (Perstedt \& Tuhkanen, 2017). Although the causes of failure of rotating equipment are very often related to the phenomena of wear of the rotating elements and vibration (El Adraoui, Gziri, and Mousrij, 2020a), performances of the compressors deteriorates due to detrimental effects of fouling on the aerodynamic flow characteristic (Hanachi, Liu, Banerjee, and Chen, 2016; Jombo, Pecinka, Sampath, and Mba, 2018; Zagorowska, Spüntrup, Ditlefsen, Imsland, Lunde, and Thornhill, 2020). Faced with all its causes of degradation, predictive maintenance seems to be the most suitable solution to improve the availability of rotating machines (Hanachi et al., 2016; El Adraoui, Gziri, and Mousrij, 2020b; Jeong, Son, Cho, Baik, and Lee, 2020). By implementing the data-driven approach for the prediction of rotating machine parameters, several works have been done. In this direction, Hanachi et al. (2016) implemented an ANFIS model to predict compressor fouling. They noted at the end of their study that filter quality and clogging can hinder compressor performance. Hence, the need to predict both the phenomena of cooler fouling and filter clogging.

In line with the previously presented work, this work deals with the proposal of a new prediction architecture based on MANFIS-PID type systems for the integration of future maintenance actions with the prediction of several parameters. This architecture has the particularity of allowing the prediction of several parameters while integrating a future maintenance action that does not modify the values of all parameters. An application to the ATLAS COPCO compressor is made to predict both the fouling of the coolers and the clogging of the filters while integrating a future maintenance action that remedies the clogging of the oil and air filters, and the fouling of the oil cooler, without however remedying the fouling of the air coolers.

We can therefore say that the major contributions of this work are firstly the simultaneous prediction of the phenomena of fouling of coolers and clogging of filters. In a second time, one of the contributions of this work is the proposal of a model allowing to integrate a partial future maintenance action to the prediction. These contributions are done with the achievement of good prediction performance with a reduced computation time.

In this article, section 2 combines the study of the operation of the ATLAS COPCO compressor with an analysis of compressor failure modes coupled with that of the significant parameters of its degradation. The ANFIS, MANFIS and MANFIS-PID systems as well as the proposed model are presented. Section 3 entitled Results and Discussion presents the performance analysis of the proposed prediction model. The conclusion and perspectives associated with this work are presented in section 4 . 


\section{MATERIALS AND METHODS}

This section presents in first, the ATLAS COPCO ZR 200 series compressor and an analysis of the failure modes which combines the significant parameters of compressor degradation. Secondly, this section presents the Neuro-Fuzzy systems implemented for the prediction of compressor failures.

\subsection{ATLAS COPCO compressor ZR 200 series}

One of the ALTLAS COPCO ZR200 series compressors present at SOCAVER (Cameroonian Glass Company) in Douala-Cameroon allowed us to validate our prediction system. Indeed, the process implemented at SOCAVER for the manufacture of hollow glass enclosures is the blownblown process. This process requires an air supply in the socalled blank mold for the formation of the blank and also an air supply in the so-called finisher mold for obtaining the final shape of the bottle. However, the production of compressed air is essential for the productivity of this company.

As presented in Figure 1, the air sucked in via the air filter is compressed in the low pressure compressor element and is delivered to the intercooler $\mathrm{Ci}$.

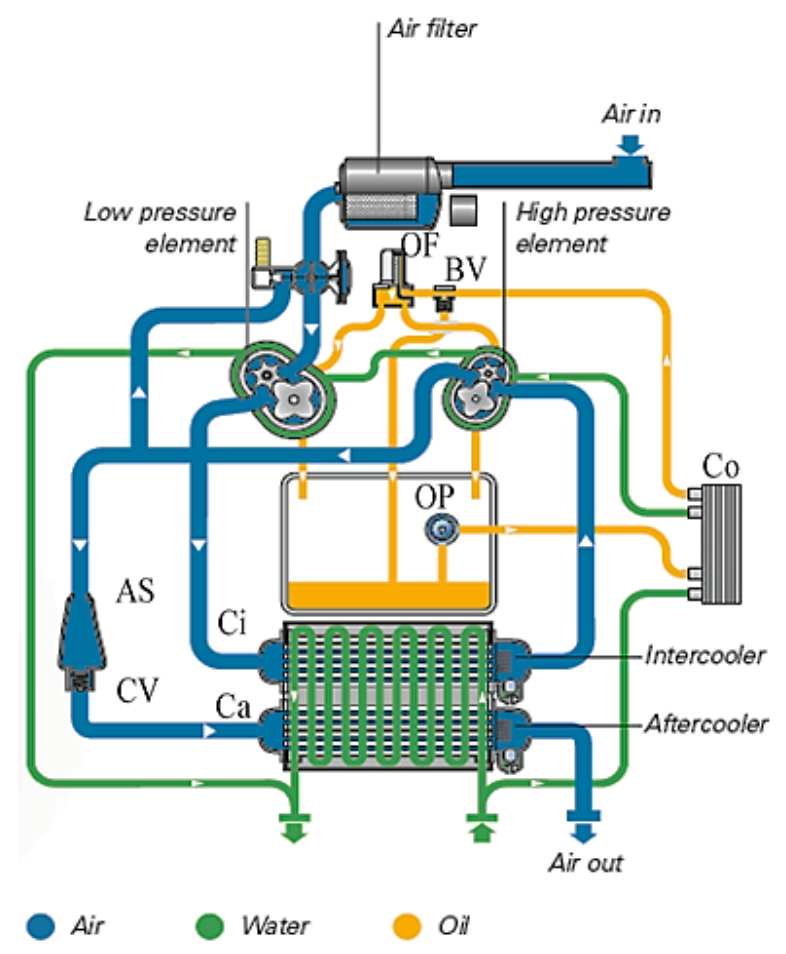

Figure 1. ZR200 compressor flow diagram (Atlas Copco, 2014)

The cooled air is then further compressed in the high pressure compressor element and discharged through the silencer AS and the aftercooler $\mathrm{Ca}$. Compressed air leaves the compressor via the air outlet. The cooling water flows through the oil cooler Co, the cooling jackets of the high pressure compressor element and the low pressure compressor element, the intercooler $\mathrm{Ci}$ and the aftercooler $\mathrm{Ca}$.

Two water separators are installed: one downstream of the intercooler to prevent the intrusion of condensates (water molecules from air condensation) into the high pressure compressor element and the other downstream of the chiller end to prevent the intrusion of condensate into the air outlet pipe. The OP oil pump conveys the oil from the gear case and through the $\mathrm{CO}$ cooler. The oil then passes through the OF oil filter, to the bearings and timing gears. The BV bypass valve opens if the oil pressure rises above a certain value.

On ATLAS COPCO compressors, the parameters measured are as follows:

- Charging and running hours

- Oil temperature $\left(T_{h}\right)$

- $\quad$ Oil pressure $\left(P_{h}\right)$

- Pressure difference at the outlet of the air filter $(P f)$

- Cooling water inlet temperature $\left(T_{e e}\right)$

- Cooling water outlet temperature $\left(T_{s e}\right)$

- Temperature at the low pressure compressor element $\left(T_{l e t}\right)$

- Temperature at the inlet of the high pressure compressor element $\left(T_{e 2 e t}\right)$

- Temperature at the outlet of the high pressure compressor element $\left(T_{s 22 t}\right)$

- Inlet pressure on the high pressure compressor element $\left(P_{\text {azet }}\right)$

- Outlet pressure on the high pressure compressor element $\left(P_{s 2 e t}\right)$

- Pressure delivered by the compressor to the network $\left(P_{r}\right)$

- Air temperature at the compressor outlet $\left(T_{s c}\right)$.

\subsubsection{Analysis of significant parameters of compressor degradation}

The analysis of failure modes and associated parameters is presented in Table 1. This analysis combines the failure mode analysis with an analysis of the parameters characterizing the evolution of a compressor element towards a failure mode. It allowed us to observe that the major parameters to take into account to implement our prediction models are:

- Temperatures at the low and high pressure compressor element $\left(T_{l e t}\right.$ et $\left.T_{s 2 e t}\right)$

- $\quad$ Oil temperature and Oil pressure $\left(T_{h}\right.$ et $\left.P_{h}\right)$

- Pressure difference at the outlet of the air filter $(P f)$. 
The abnormal evolution of these parameters reflects the appearance of fouling phenomena in the air and oil coolers, and clogging of the air and oil filters. The occurrence of these failure modes results in adverse effects such as:
- Non-conformity of the air pressure and temperature at the outlet

- Lubrication fault.

Table 1. Analysis of failure modes and associated parameters

\begin{tabular}{|c|c|c|c|c|}
\hline Element & Function & Failure mode & Effect on compressor & Parameters \\
\hline Air filter & Rid the air of impurities & Clogged filter & $\begin{array}{l}\text { Non-compliance of the air pressure } \\
\text { at the outlet }\end{array}$ & $P f$ \\
\hline \multirow{2}{*}{$\begin{array}{l}\text { low pressure } \\
\text { compressor } \\
\text { element }\end{array}$} & \multirow[t]{2}{*}{$\begin{array}{l}\text { Compress the air at low } \\
\text { pressure }\end{array}$} & Abnormal heating & $\begin{array}{l}\text { Non-compliance of the air } \\
\text { temperature at the outlet }\end{array}$ & $T_{l e t}$ and $T_{e 2 e t}$ \\
\hline & & $\begin{array}{l}\begin{array}{l}\text { Non-compliance of the } \\
\text { delivered pressure }\end{array}\end{array}$ & $\begin{array}{l}\text { Non-compliance of the air pressure } \\
\text { at the outlet }\end{array}$ & $\mathrm{P}_{\mathrm{a} 2 \mathrm{et}}$ \\
\hline \multirow{2}{*}{$\begin{array}{l}\text { high pressure } \\
\text { compressor } \\
\text { element }\end{array}$} & \multirow[t]{2}{*}{$\begin{array}{l}\text { Compress air at high } \\
\text { pressure }\end{array}$} & Abnormal heating & $\begin{array}{l}\text { Non-compliance of the air } \\
\text { temperature at the outlet }\end{array}$ & $T_{s 2 e t}$ and $T_{s c}$ \\
\hline & & $\begin{array}{lll}\begin{array}{l}\text { Non-compliance } \\
\text { delivered pressure }\end{array} & \text { of the } \\
\end{array}$ & $\begin{array}{l}\text { Non-compliance of the air pressure } \\
\text { at the outlet }\end{array}$ & $P_{s 2 e t}$ \\
\hline $\begin{array}{l}\text { Synchronization } \\
\text { gears }\end{array}$ & $\begin{array}{l}\text { Drive the screws of the low } \\
\text { and high pressure } \\
\text { compressor element }\end{array}$ & Pinions sprockets & $\begin{array}{l}\text { - Abnormal vibration } \\
\text { - Screw drive faults }\end{array}$ & \\
\hline Water separators & $\begin{array}{l}\text { Clean the air of water } \\
\text { particles }\end{array}$ & $\begin{array}{l}\text { The separator does not } \\
\text { separate the air from the } \\
\text { condensate }\end{array}$ & Air non-compliance & \\
\hline Intercooler & $\begin{array}{l}\text { Cool the air at the exit of the } \\
\text { low pressure compressor } \\
\text { element }\end{array}$ & Fouled cooler & $\begin{array}{l}\text { Non-compliance of the air } \\
\text { temperature at the entrance to the } \\
\text { high pressure compressor element }\end{array}$ & $T_{e 2 e t}$ \\
\hline Aftercooler & $\begin{array}{l}\text { Cool the air at the exit of the } \\
\text { high pressure compressor } \\
\text { element }\end{array}$ & Fouled cooler & $\begin{array}{l}\text { Non-compliance of the air } \\
\text { temperature at the outlet of the high } \\
\text { pressure compressor element }\end{array}$ & $T_{s c}$ \\
\hline Silencer & Reduce noise & Silencer not tight & Abnormal noise & \\
\hline Non-return valve & $\begin{array}{l}\text { Prevent air circulation in } \\
\text { two directions }\end{array}$ & $\begin{array}{l}\text { The valve does not prevent } \\
\text { the return of the fluid }\end{array}$ & Non-compliant pressure & $P_{r}$ \\
\hline Oil pump & $\begin{array}{l}\text { Converting mechanical } \\
\text { energy into hydraulic } \\
\text { energy }\end{array}$ & $\begin{array}{l}\text { The pump does not deliver or } \\
\text { delivers little oil }\end{array}$ & Lubrication fault & $P_{h}$ \\
\hline Oil filter & Rid the oil of impurities & Clogged filter & Lubrication fault & $P_{h}$ \\
\hline Oil cooler & Cool the oil & Fouled cooler & Lubrication fault & $T_{h}$ \\
\hline
\end{tabular}

The analysis of the ATLAS COPCO compressor parameters aims at establishing the interdependence relations between the parameters to be predicted. To establish the interdependence relationships between the significant parameters of the ATLAS COPCO compressor degradation, we have first calculated and observed the correlation coefficients. In a second step, we based ourselves on the analysis of the compressor operation.

The rank Spearman correlation (Lobo \& Guntur, 2018), is calculated by applying the Eq. (1):

$$
\rho=1-\frac{6 \sum d_{i}^{2}}{\mathrm{n}\left(n^{2}-1\right)}
$$

With:

$\rho$ : Spearman rank correlation value $d$ : Margin of each pair value $n$ : Spearman rank pair values.

Table 2 presents the Spearman correlation coefficients of the characteristic parameters of the phenomena of fouling of the coolers, and clogging of the filters of the ATLAS COPCO compressor. It is from the analysis of the values of these coefficients, completed by the analysis of the compressor operation, that we establish the interdependence relations between the parameters to be predicted as described in Eq. (2). For the parameter $T_{\text {let }}$, we are interested in the parameters so the correlation coefficients are greater than or equal to 0.48. For the parameters $P_{h}$ and $T_{s 2 e t}$, we have taken into account parameters so the correlation coefficients are greater than or equal to 0.42 . For the parameter $T_{h}$, we chose the parameters so the correlation coefficients are higher or equal to 0.63 . Finally for the parameter $P f$, we have taken into 
account the parameter whose correlation coefficient is equal to 1 .

Table 2. Spearman correlation coefficients

\begin{tabular}{|c|l|l|l|l|l|}
\hline & $\boldsymbol{T}_{1 \text { et }}$ & $\boldsymbol{T}_{\boldsymbol{s 2 e t}}$ & $\boldsymbol{T}_{\boldsymbol{h}}$ & \multicolumn{1}{|c|}{$\boldsymbol{P}_{\boldsymbol{h}}$} & $\boldsymbol{P} \boldsymbol{f}$ \\
\hline$T_{1 \text { et }}$ & 1 & 0.42 & 0.63 & 0.11 & 0.45 \\
\hline$T_{\text {s2et }}$ & 0.42 & 1 & 0.67 & 0.15 & 0.23 \\
\hline$T_{h}$ & 0.63 & 0.67 & 1 & 0.42 & 0.01 \\
\hline$P_{h}$ & 0.11 & 0.15 & 0.42 & 1 & 0.02 \\
\hline$P f$ & 0.45 & 0.23 & 0.01 & 0.02 & 1 \\
\hline$T_{e e}$ & 0.66 & 0.62 & 0.50 & 0.22 & 0.04 \\
\hline
\end{tabular}

$$
\left\{\begin{array}{c}
\frac{d T_{1 e t}}{d t}=f_{1}\left(T_{1 e t}, P f, T_{e e}, T_{h}\right) \\
\frac{d T_{s 2 e t}}{d t}=f_{2}\left(T_{s 2 e t}, T_{e e}, T_{1 e t}, T_{h}\right) \\
\frac{d T_{h}}{d t}=f_{3}\left(T_{h}, T_{e e}, T_{1 e t}, T_{s 2 e t}\right) \\
\frac{d P_{h}}{d t}=f_{4}\left(P_{h}, T_{h}\right) \\
\frac{d P f}{d t}=f_{5}(P f)
\end{array}\right.
$$

\subsection{Adaptive Neuro Fuzzy Inference System (ANFIS)}

The ANFIS system presented in Figure 2, proposed by Jang et al. (1997), is a multilayer adaptive network-based fuzzy inference that maps relations between inputs and outputs. ANFIS is useful for solving complex problems with large uncertainties by creating a fuzzy inference system with adjusted parameters of the membership function (Zid, Ahmed, and Turki, 2018; Elbaz, Shen, Sun, Yin, and Zhou, 2020).

In this work, ANFIS model is used for the following reasons:

- ANFIS allows reduced computation time (Cao, Babanezhad, Rezakazemi, and Shirazian, 2020)

- Neuro-fuzzy systems are promising in cases where limited data are available (Adeline et al., 2008; Hanachi et al., 2018; Atsalakis, Atsalaki, and Zopounidis, 2018)

- The function fitting degree can be controlled in the membership functions regarding the sensitivity to each input, and it shows high repeatability for parameter setting when it is trained with the training data set (Hanachi, Jie, and Mechefske, 2018)

- ANFIS requires fewer adjustable parameters than those required in other Neural Network structures (Atsalakis et al., 2018; Naphon, Arisariyawong, Wiriyasart, and Srichat, 2020).

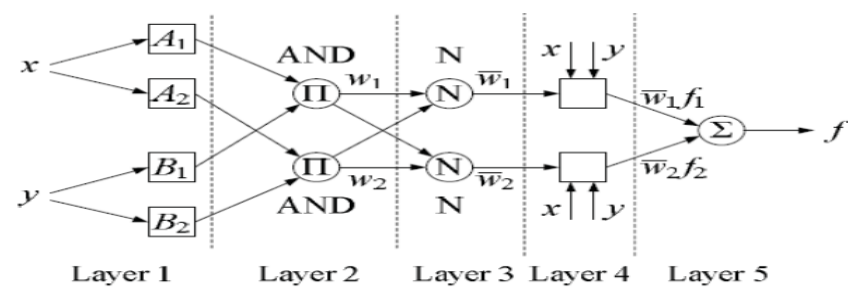

Figure 2. Network structure of ANFIS model (Jang et al., 1997)

An ANFIS system implements a linear approximation of the output variable by decomposing the input space into different fuzzy spaces. An ANFIS system is composed of five layers.

Layer 1. Generates the membership grades:

$$
\begin{gathered}
O_{i}^{1}=\mu_{A_{i}}(x), \mathrm{i}=1,2 \\
O_{i}^{1}=\mu_{B_{i}}(y), \mathrm{i}=1,2
\end{gathered}
$$

Where $\mu_{A i}$ and $\mu_{B i}$ can be any membership functions.

Layer 2. Generates the firing strengths.

$$
O_{i}^{2}=w_{i}=\mu_{A_{i}}(x) \mu_{B i}(y), \mathrm{i}=1,2
$$

Layer 3. Normalizes the firing strengths.

$$
O_{i}^{3}=\overline{w_{l}}=\frac{w_{i}}{w_{1}+w_{2}}, \mathrm{i}=1,2
$$

Layer 4. Calculates rule outputs based on the consequent parameters.

$$
O_{i}^{4}=\bar{w}_{\imath} f_{i}=\bar{w}\left(p_{i} x+q_{i} y+r_{i}\right), \mathrm{i}=1,2
$$

Where $p_{\mathrm{i}}, q_{\mathrm{i}}$ and $r_{\mathrm{i}}$ are the so-called consequential parameters.

Layer 5. Output calculation

$$
O_{i}^{5}=\sum_{i=1}^{2} \overline{w_{l}} f_{i}=\frac{\sum_{i=1}^{2} w_{i} f_{i}}{w_{1}+w_{2}}, \mathrm{i}=1,2
$$

After this phase, the optimal values of these membership function parameters and consequential parameters are set by a hybrid learning algorithm that combines the method of least squares with the backpropagation learning algorithm (Abdulshahed, Longstaff, Fletcher, and Myers, 2013). Finally, the ANFIS output is calculated by means of consequential parameters (Jang, 1993). Different learning techniques, such as a hybrid-learning algorithm (Kar, Das, and Ghosh, 2014) or Genetic Algorithm (Martínez-Soto, Castillo, and Castro, 2014), can be adopted to solve this training problem. Better performance of ANFIS models has been shown by adopting a rapid hybrid learning method, which integrates the gradient descent method and the leastsquares method optimize parameters (Karahoca, \& Karahoca, 
2011).Thus in this paper, the hybrid learning method is used for constructing the proposed models.

The "Fuzzy C-Means clustering" (FCM) method is based on the principle that each data point belongs to a "cluster" to some extent which is specified by a membership category. This method offers better partitioning compared to other methods. It allows a set of points belonging to a multidimensional space to be grouped into a specific number of different clusters. FCM uses fuzzy partitioning allowing a data point to belong to all groups with different membership degrees between 0 and 1. Suganya \& Shanthi (2012) provide a synthetic algorithm for this method.

The implementation of FCM begins with the calculation of the vector of the centers of the "clusters". For each of the $\mathrm{k}$ iterations, the following expression makes it possible to calculate the centers of the "clusters".

$$
C_{i}=\frac{\sum_{j=1}^{n} u_{i j}^{m} x_{j}}{\sum_{j=1}^{n} u_{i j}^{m}}
$$

$x_{i}$ is the $i^{\text {th }}$ datum measured in d-dimensional space. The degree to which xi belongs to the "cluster" $\mathrm{j}$ is denoted by $u_{i j}$. The centers thus calculated allow the degrees of membership to be corrected via the expressions below:

$$
\begin{aligned}
& u_{i j}=\frac{1}{\sum_{k=1}^{c}\left(\frac{d_{i j}}{d_{k j}}\right)^{2 /(m-1)}} \\
& d_{i j}=\sqrt{\sum_{i=1}^{n}\left(x_{i}-c_{i}\right)}
\end{aligned}
$$

The membership degrees are corrected until:

$$
\|U(k+1)-U(k)\|<\epsilon
$$

\subsection{Multi-outputs Adaptive Neuro-Fuzzy Inference System (MANFIS)}

The MANFIS architecture presented in Figure 3 is seen as an aggregation of several ANFIS. The first MANFIS architecture was proposed by Jang \& Sun (1995).

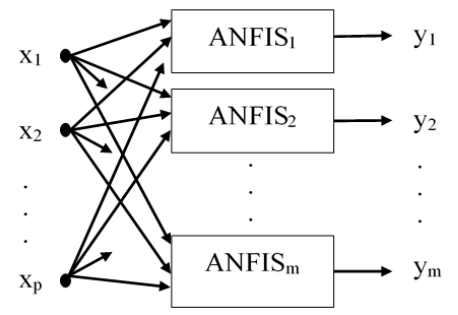

Figure 3. MANFIS proposed by Jang \& Sun (1995)

It is among other things to improve the performance of this prediction architecture that Tjahe et al. (2017a) proposed a new MANFIS system (shown in Figure 4), that takes into account the four previous instants to predict the next instant for the prediction of three interrelated parameters.

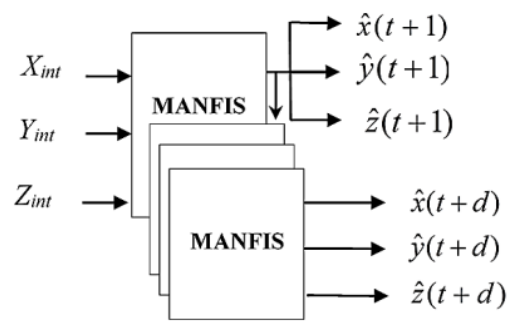

Figure 4. MANFIS for the prediction of three interdependent parameters proposed by Tjahe et al. (2017a) In figure 4 input variables $X_{i n t}, Y_{i n t}$ and $Z_{i n t}$ are vectors defined as follows:

$$
\begin{aligned}
& X_{\text {int }}=\left[\begin{array}{llll}
x(t-3) & x(t-2) & x(t-1) & x(t)
\end{array}\right]^{T} \\
& Y_{\text {int }}=\left[\begin{array}{llll}
y(t-3) & y(t-2) & y(t-1) & y(t)
\end{array}\right]^{T} \\
& Z_{\text {int }}=\left[\begin{array}{llll}
z(t-3) & z(t-2) & z(t-1) & z(t)
\end{array}\right]^{T}
\end{aligned}
$$

\subsection{MANFIS-PID}

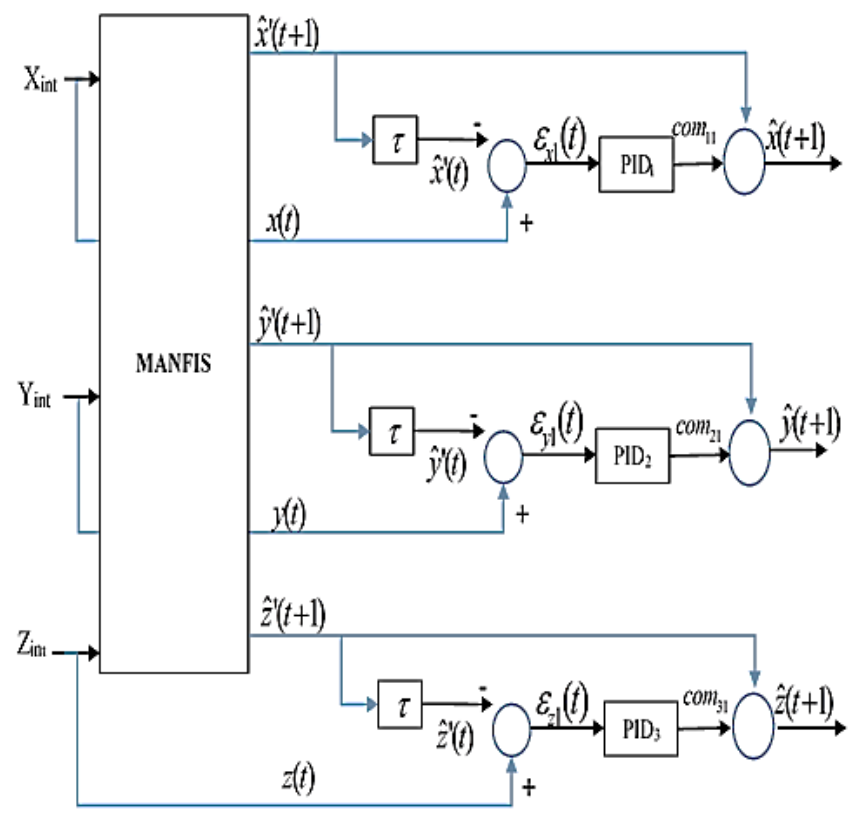

Figure 5. MANFIS-PID system (Tjahe et al. 2017b)

The MANFIS-PID system shown in Figure 5 consists of a MANFIS system that takes into account the four previous instants to predict the next instant (Tjahe et al. 2017a). PID controllers are associated with this system, with the aim of reducing the prediction error (Tjahe et al. 2017b). Unlike the PID controller proposed by Zemouri et al. (2010), the 
particularity of the PID controllers proposed here is that they keep constant, parameter values $K_{p}, K_{i}$ and $K_{d}$ in the medium term.

For the MANFIS-PID system, the prediction errors $\mathcal{E}_{x l}(t)$, $\mathcal{E}_{y 1}(t)$ and $\mathcal{E}_{\mathrm{zl}}(\mathrm{t})$ are respectively calculated between the values $\hat{x}^{\prime}(t), \hat{y}^{\prime}(t)$ and $\hat{z}^{\prime}(t)$ predicted by the MANFIS subsystem and the real values $x(t), y(t)$ and $z(t)$. The controllers $\mathrm{PID}_{1}, \mathrm{PID}_{2}$ and $\mathrm{PID}_{3}$ respectively deliver the commands $\operatorname{com}_{11}, \operatorname{com}_{21}$ and $\operatorname{com}_{31}$ capable of adjusting the predictions of the MANFIS subsystem. The control of the prediction error thus performed allows us to obtain $\hat{x}(t+1)$, $\hat{y}(t+1)$ and $\hat{z}(t+1)$.

\subsubsection{Determination of the optimal parameters of PID controllers}

The method for calculating the parameters $K_{p}, K_{i}$ and $K_{d}$ of PID controllers is described below.

Consider the variable $x$, the control of the prediction error can be written:

$$
\begin{aligned}
\hat{x}(t+1)=\hat{x}^{\prime}(t+1) & +K_{P} \varepsilon_{x 1}(t) \\
& +K_{i} \int_{0}^{t} \varepsilon_{x 1}(\tau) d \tau \\
& +K_{d} \frac{\partial \varepsilon_{x 1}(t)}{\partial t}
\end{aligned}
$$

With $\mathcal{E}_{x l}(\mathrm{t})$ the prediction error for the horizon $t+1$. By induction, at the horizon $\mathrm{t}+\mathrm{d}$ we can also write:

$$
\begin{aligned}
\hat{x}(t+d)=\hat{x}^{\prime}(t & +d)+K_{P} \varepsilon_{x d}(t) \\
& +K_{i} \int_{0}^{t} \varepsilon_{x d}(\tau) d \tau \\
& +K_{d} \frac{\partial \varepsilon_{x d}(t)}{\partial t}
\end{aligned}
$$

With $\mathcal{E}_{x d}(\mathrm{t})$ the prediction error for the horizon $t+d$.

The command $c_{11}$ delivered by the $\mathrm{PID}_{1}$ controller to predict the state of the variable $X$ at instant $t+1$ can be written as:

$$
\operatorname{com}_{11}=K_{P} \varepsilon_{x 1}(t)+K_{i} \int_{0}^{t} \varepsilon_{x 1}(\tau) d \tau+K_{d} \frac{\partial \varepsilon_{x 1}(t)}{\partial t}
$$

The ideal being that :

$$
\operatorname{com}_{11}=\hat{x}(t+1)-\hat{x}^{\prime}(t+1)
$$

Similarly, the command com $1 d$ delivered by the $\mathrm{PID}_{1}$ controller at time $t+d$ can be written:

$$
\operatorname{com}_{1 d}=\hat{x}(t+d)-\hat{x}^{\prime}(t+d)
$$

Ideally,

$$
\hat{x}(t+d)=x(t+d)
$$

This implies that:

$$
\operatorname{com}_{1 d}=\hat{x}(t+d)-\hat{x}^{\prime}(t+d)
$$

Considering the previous expressions, there are constant and optimal values $K_{p}, K_{i}$ and $K_{d}$ satisfying the following equation system:

$$
\left\{\begin{array}{c}
\operatorname{com}_{11}=K_{P} \varepsilon_{x 1}(t)+K_{i} \int_{0}^{t} \varepsilon_{x 1}(\tau) d \tau \\
+K_{d} \frac{\partial \varepsilon_{x 1}(t)}{\partial t} \\
\cdot \cdot \\
\operatorname{com}_{1 d}=K_{P} \varepsilon_{x d}(t)+K_{i} \int_{0}^{t} \varepsilon_{x d}(\tau) d \tau \\
+K_{d} \frac{\partial \varepsilon_{x d}(t)}{\partial t}
\end{array}\right.
$$

The same approach is applied to the variables $y$ and $z$.

\subsection{Architecture for integrating future maintenance actions into the prediction}

The prediction architecture integrating future maintenance actions consists of three systems of the MANFIS-PID type (Figure 6).

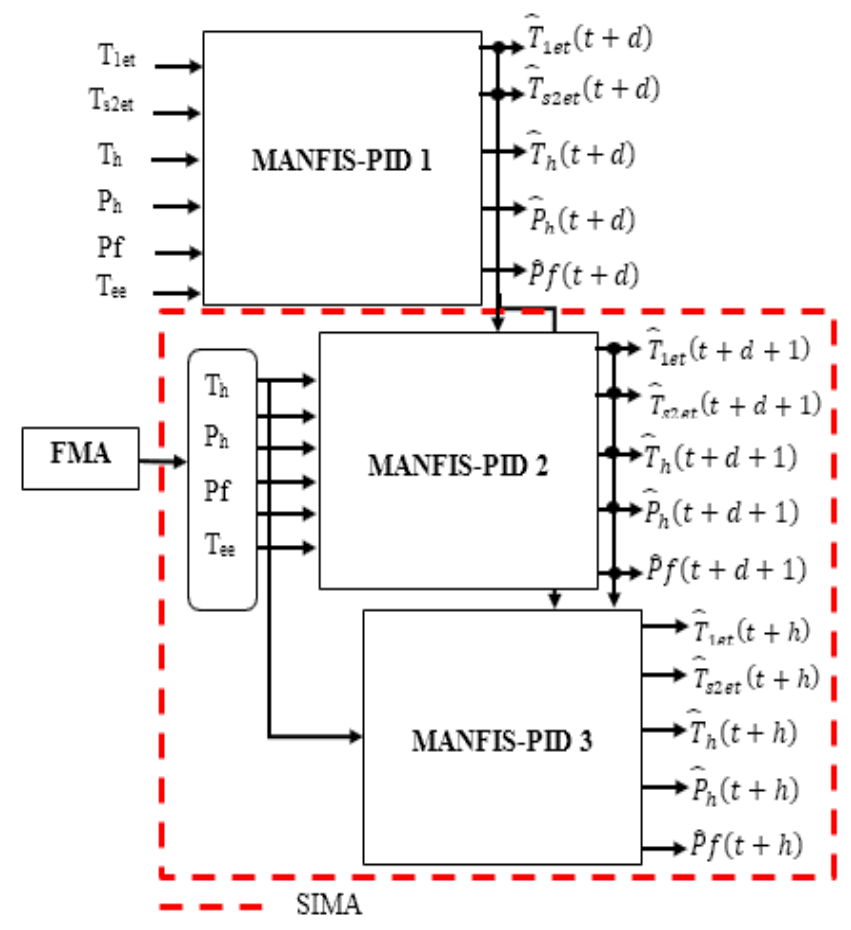

Figure 6. Architecture for integration of future maintenance action 
The MANFIS-PID1 system is that proposed by Tjahe et al. (2017b). The MANFIS-PID2 and MANFIS-PID3 systems constitute the System for Integrating Maintenance Action (SIMA).

In this architecture, the new constraint integrated into the prediction by the SIMA is considered as a modification of the evolution profile due to a scheduled maintenance action. The Future Maintenance Action (FMA) shown in Figure 6 consists in remedying the problems related to water overheating, oil cooler fouling and air and oil filter clogging. Therefore, the FMA initializes the parameters $T_{h}, P_{h}, P f$ and $T_{e e}$.

We therefore assume that the MANFIS-PID1 system is able to predict the evolution of the compressor parameters $T_{l e t}$, $T_{s 2 e t}, T_{h}, P_{h}$ and $P f$ until all failure thresholds are reached. That is to say, until both air and oil cooler fouling and air and oil filter clogging are observed. In this case, the SIMA allows to know how long the compressor could continue to operate after a possible modification of the parameters $T_{h}, P_{h}, P f$ and $T_{e e}$ by the execution of the FMA.

The input parameters of the MANFIS-PID1 system are vectors presented as follows:

$$
\begin{aligned}
& T_{1 e t}=\left[T_{1 e t}(t-3) T_{1 e t}(t-2) T_{1 e t}(t-\right. \\
& \text { 1) } \left.T_{1 e t}(t)\right]^{T}
\end{aligned}
$$

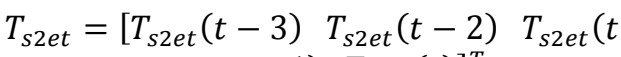

$$
\begin{aligned}
& \text {-1) } \left.T_{s 2 e t}(t)\right]^{T} \\
& T_{h}=\left[\begin{array}{llll}
T_{h}(t-3) & T_{h}(t-2) & T_{h}(t-1) & T_{h}(t)
\end{array}\right]^{T} \\
& P_{h}=\left[\begin{array}{llll}
P_{h}(t-3) & P_{h}(t-2) & P_{h}(t-1) & P_{h}(t)
\end{array}\right]^{T} \\
& P f=[P f(t-3) \quad P f(t-2) \quad P f(t \\
& \text {-1) } P f(t)]^{T} \\
& T_{e e}=\left[T_{e e}(t-3) T_{e e}(t-2) T_{e e}(t\right. \\
& \text {-1) } \left.T_{e e}(t)\right]^{T}
\end{aligned}
$$

From instant $\mathrm{t}$, if MANFIS-PID1 predicts the simultaneous attainment of critical thresholds of the parameters $T_{\text {let }}, T_{s 2 e t}$, $T_{h}, P_{h}$ and $P f$ at time $t+d$, SIMA can be used to incorporate a FMA into the prediction. In this case to integrate Future Maintenance Actions (FMA) into the prediction by SIMA, we consider the possibility that the compressor has the following failures:

- Fouling of the oil cooler detectable by $T_{h}$

- Clogged air filter detectable by $P f$

- Clogged oil filter detectable by $P_{h}$

- $\quad$ Air cooler fouling detectable by $T_{\text {let }}$ and $T_{s 2 e t}$.
We include in the prediction the possibility of FMA that correct all faults except the clogging of the air cooler. These FMA only modify $T_{h}, P_{h}, P f$ and $T_{e e}$, at time $t+d$. The time $t+d$ is therefore the time from which we would like to know how long the equipment could still function despite the partial correction of its failures.

The inputs of the MANFIS-PID2 system are those obtained after the execution of the FMA at time $t+d\left(T_{h}, P_{h}, P f\right.$ and $T_{e e}$ ), and the four respective previous states of $T_{\text {let }}$ and $T_{s 2 e t}$ because fouling in the air cooler has not been corrected.

The input parameters of the MANFIS-PID2 system are vectors presented in Eq. (30) to Eq. (35):

$$
\begin{aligned}
& T_{1 e t}=\left[\widehat{T}_{1 e t}(t+d-3) \widehat{T}_{1 e t}(t+d-2) \widehat{T}_{1 e t}(t\right. \\
& \left.+d-1) \widehat{T}_{1 e t}(t+d)\right]^{T} \\
& T_{s 2 e t}=\left[\widehat{T}_{s 2 e t}(t+d-3) \widehat{T}_{s 2 e t}(t+d\right. \\
& \text {-2) } \widehat{T}_{s 2 e t}(t+d-1) \widehat{T}_{s 2 e t}(t \\
& +d)]^{T}
\end{aligned}
$$

The values of the parameters $T_{h}, P_{h}, P f$ and $T_{e e}$ at the input of the MANFIS-PID2 system are those modified by the FMA, and are considered as the real values at time $t+d$, as described by Eq. (32), Eq. (33), Eq. (34) and Eq. (35).

$$
\begin{gathered}
T_{h}=\left[T_{h}(t+d)\right]^{T} \\
P_{h}=\left[P_{h}(t+d)\right]^{T} \\
P f=[P f(t+d)]^{T} \\
T_{e e}=\left[T_{e e}(t+d)\right]^{T}
\end{gathered}
$$

For the parameters $T_{h}, P_{h}, P f$ and $T_{e e}$, the MANFIS-PID3 system values the values obtained after the maintenance action and those predicted by the MANFIS-PID2 system as well as the four respective previous states of $T_{\text {let }}$ and $T_{s 2 e t}$.

The cascading of MANFIS-PID2 and MANFIS-PID3 in SIMA is done for two main reasons:

- To increment the prediction horizon

- To improve the prediction performance, because MANFIS-PID3 takes into account more previous instants than MANFIS-PID2 for the parameters $T_{h}, P_{h}$, $P f$ and $T_{e e}$ as presented from Eq. (38) to Eq. (41)

The input parameters of the MANFIS PID3 system are vectors presented as follows: 


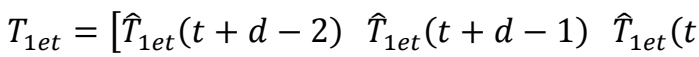

$$
\begin{aligned}
& \text { +d) } \left.\hat{T}_{1 e t}(t+d+1)\right]^{T} \\
& T_{s 2 e t}=\left[\widehat{T}_{s 2 e t}(t+d-2) \widehat{T}_{s 2 e t}(t+d-\right. \\
& \text { 1) } \left.\hat{T}_{s 2 e t}(t+d) \hat{T}_{s 2 e t}(t+d+1)\right]^{T} \\
& T_{h}=\left[\begin{array}{ll}
T_{h}(t+d) & \widehat{T}_{h}(t+d+1)
\end{array}\right]^{T} \\
& P_{h}=\left[\begin{array}{ll}
P_{h}(t+d) & \widehat{P}_{h}(t+d+1)
\end{array}\right]^{T} \\
& P f=[P f(t+d) \hat{P} f(t+d+1)]^{T} \\
& P f=[P f(t+d) \hat{P} f(t+d+1)]^{T}
\end{aligned}
$$

From time $t$, the prediction architecture proposed in Figure 6 allows to predict the evolution of the compressor parameters until time $t+h$ knowing that a partial FMA could be performed at time $t+d$.

The variables $d$ and $h$ are prediction horizons, with:

$$
h>d+1
$$

\section{RESULTS AND DISCUSSION}

The objective of this study was to analyze and evaluate in a first step the capacity of a MANFID-PID type architecture based on the consideration of the four previous instants and the control of the prediction error, to predict in the short term the fouling of the air and oil coolers and the clogging of the air and oil filters using the parameters considered significant of the degradation of the ATLAS COPCO compressor. In a second step, the performance of prediction of this architecture was evaluated and analyzed in the event that an initial prediction would have revealed that the compressor will have both fouling of the air and oil coolers and clogging of the air and oil filters. In this eventuality the particularity is that we integrate to the prediction a future partial maintenance action that corrects the fouling of the oil coolers and the clogging of the air and oil filters, but does not correct the fouling of the air coolers. To achieve this goal, this study was performed with a sample of 30 training data and 47 test data. These data are collected at daily time step. We tested the ability of the MANFIS-PID1 and SIMA systems to predict the values of the significant compressor degradation parameters $\left(T_{\text {let }}, T_{s 2 e t}\right.$, $T_{h}, P_{h}$ and $\left.P f\right)$ at different prediction horizons. These prediction horizons range from one to four days.

\subsection{Performance measures used in this study}

Four performance indicators are assessed here. We evaluate mean squared error (RMSE), Accuracy (Acc) and $\mathrm{R}^{2}$ (Chai \& Draxler 2014; Bayatzadeh, Ghadimi and Fattahi, 2017; Hyndman \& Koehler 2006; Wong, Arumugasamy, Chung, Selvarajoo, and Sethu, 2020). The last indicator is the computational time, CPU (Central Processing Unit) in seconds (s).

$$
R M S E=\sqrt{\frac{1}{n} \sum_{i=1}^{n}\left(x_{i}-\widehat{x}_{l}\right)^{2}}
$$

With $x_{\mathrm{i}}$ the actual measured data and $\hat{x}_{i}$ the predicted data.

$$
\begin{gathered}
R^{2}=1-\frac{\sum_{i=1}^{n}\left(x_{i}-\widehat{x}_{l}\right)^{2}}{\sum_{i=1}^{n} x_{i}^{2}-\frac{\sum_{i=1}^{n} \widehat{x}_{l}^{2}}{n}} \\
A c c=1-\frac{1}{n} \sum_{i=1}^{n} \frac{\left|x_{i}-\widehat{x}_{l}\right|}{\left(\left|x_{i}\right|+\left|\widehat{x}_{l}\right|\right) / 2}
\end{gathered}
$$

\begin{tabular}{|c|c|c|c|c|c|}
\hline Parameter & Performances & $\begin{array}{l}\mathbf{t}+\mathbf{1} \\
\text { days } \\
\end{array}$ & $\begin{array}{l}t+2 \\
\text { days } \\
\end{array}$ & $\begin{array}{l}\mathbf{t}+\mathbf{3} \\
\text { days } \\
\end{array}$ & $\begin{array}{l}\mathrm{t}+4 \\
\text { days } \\
\end{array}$ \\
\hline \multirow[t]{4}{*}{$T_{\text {let }}$} & $\mathbf{R}^{2}$ & 0.73 & 0.73 & 0.72 & 0.72 \\
\hline & RMSE $\left({ }^{\circ} \mathrm{C}\right)$ & 1.57 & 1.87 & 2.10 & 2.36 \\
\hline & ACC & 0.76 & 0.76 & 0.75 & 0.75 \\
\hline & CPU Time (s) & 35.5 & 40.21 & 40.35 & 40.30 \\
\hline \multirow[t]{4}{*}{$T_{s 2 e t}$} & $\mathbf{R}^{2}$ & 0.72 & 0.72 & 0.71 & 0.68 \\
\hline & RMSE $\left({ }^{\circ} \mathrm{C}\right)$ & 1.65 & 1.97 & 2.4 & 2.5 \\
\hline & $\mathbf{A C C}_{\mathbf{C C}}$ & 0.76 & 0.75 & 0.73 & 0.73 \\
\hline & CPU Time (s) & 40.15 & 41.57 & 40.82 & 42.56 \\
\hline \multirow[t]{4}{*}{$\frac{T h}{T h}$} & $\mathbf{R}^{2}$ & 0.85 & 0.82 & 0.82 & 0.81 \\
\hline & RMSE $\left({ }^{\circ} \mathrm{C}\right)$ & 0.54 & 0.62 & 0.78 & 0.84 \\
\hline & $\mathbf{A}_{\mathbf{C C}}$ & 0.95 & 0.94 & 0.84 & 0.84 \\
\hline & CPU Time (s) & 28.88 & 30.14 & 30.56 & 32.58 \\
\hline \multirow[t]{4}{*}{$P_{h}$} & $\mathbf{R}^{2}$ & 0.89 & 0.87 & 0.87 & 0.85 \\
\hline & RMSE (bar) & 0.16 & 0.25 & 0.29 & 0.34 \\
\hline & $\mathbf{A}_{\mathbf{C C}}$ & 0.96 & 0.95 & 0.95 & 0.93 \\
\hline & CPU Time (s) & 27.29 & 27.12 & 27.58 & 28.56 \\
\hline \multirow{4}{*}{ Pf } & $\mathbf{R}^{2}$ & 0.93 & 0.93 & 0.90 & 0.90 \\
\hline & RMSE (bar) & 0.01 & 0.02 & 0.03 & 0.03 \\
\hline & ACC & 0.98 & 0.98 & 0.98 & 0.98 \\
\hline & CPU Time (s) & 28.69 & 28.75 & 28.36 & 29.16 \\
\hline
\end{tabular}

Table 3 and Table 4 respectively present the prediction performance of the MANFIS-PID1 and SIMA system at four different prediction horizons. These results are obtained with a computer with a 64-bit configuration, $4 \mathrm{~GB}$ of Intel (R) dual Core RAM.

Table 3. MANFIS-PID1 system performance 
Table 3 shows that until horizon $\mathrm{t}+4$ days, the RMSE is of the order of $2.3\left({ }^{\circ} \mathrm{C}\right)$ for the parameter $T_{\text {let }}$, and of $2.5\left({ }^{\circ} \mathrm{C}\right)$ for the parameter $T_{s 2 e t}$. Regarding the temperature of the oil $T_{h}$, at the horizon $\mathrm{t}+4$ days we obtained an RMSE of the order of $0.84\left({ }^{\circ} \mathrm{C}\right)$ which is satisfactory taking into account the order of magnitude of the temperature of the oil. On the other hand, the prediction of the oil pressure $P_{h}$ at the horizon $\mathrm{t}+4$ days is of the order of 0.34 (bar). The MANFIS-PID system offers good predictions of the evolution of Pf. The CPU time values do not exceed 45 seconds for the predictions of $T_{\text {let }}$ and $T_{s 2 e t}$ for the prediction of $T_{h}, P_{h}$ and $P f$ the CPU time values do not exceed 30 seconds.

As shown in Table 4, SIMA has a relatively poorer prediction performance than MANFIS-PID1.

Table 4. SIMA performance

\begin{tabular}{|c|c|c|c|c|c|}
\hline Parameter & Performances & $\begin{array}{l}\mathbf{t}+\mathbf{1} \\
\text { days }\end{array}$ & $\begin{array}{l}\mathrm{t}+2 \\
\text { days }\end{array}$ & $\begin{array}{l}\mathbf{t}+\mathbf{3} \\
\text { days }\end{array}$ & $\begin{array}{l}\mathrm{t}+4 \\
\text { days }\end{array}$ \\
\hline \multirow[t]{4}{*}{$T_{\text {let }}$} & $\mathbf{R}^{2}$ & 0.71 & 0.71 & 0.68 & 0.68 \\
\hline & RMSE $\left({ }^{\circ} \mathrm{C}\right)$ & 1.63 & 1.90 & 2.13 & 2.54 \\
\hline & ACC & 0.75 & 0.74 & 0.73 & 0.73 \\
\hline & CPU Time (s) & 40.71 & 41.52 & 41.6 & 41.58 \\
\hline \multirow[t]{4}{*}{$T_{s 2 e t}$} & $\mathbf{R}^{2}$ & 0.71 & 0.71 & 0.71 & 0.68 \\
\hline & RMSE $\left({ }^{\circ} \mathrm{C}\right)$ & 1.81 & 2.11 & 2.62 & 2.81 \\
\hline & ACC & 0.76 & 0.75 & 0.73 & 0.73 \\
\hline & CPU Time (s) & 40.46 & 40.51 & 40.45 & 40.62 \\
\hline \multirow[t]{4}{*}{$T_{h}$} & $\mathbf{R}^{2}$ & 0.75 & 0.71 & 0.70 & 0.70 \\
\hline & RMSE $\left({ }^{\circ} \mathrm{C}\right)$ & 0.61 & 0.72 & 0.81 & 0.92 \\
\hline & $\mathbf{A}_{\mathbf{C C}}$ & 0.73 & 0.73 & 0.70 & 0.70 \\
\hline & CPU Time (s) & 39.89 & 39.86 & 40.20 & 40.52 \\
\hline \multirow[t]{4}{*}{$P_{h}$} & $\mathbf{R}^{2}$ & 0.88 & 0.88 & 0.87 & 0.87 \\
\hline & RMSE (bar) & 0.18 & 0.27 & 0.31 & 0.42 \\
\hline & $\mathbf{A C C}_{\mathrm{CC}}$ & 0.92 & 0.91 & 0.90 & 0.90 \\
\hline & CPU Time (s) & 39.71 & 39.53 & 40.22 & 40.30 \\
\hline \multirow{4}{*}{$P f$} & $\mathbf{R}^{2}$ & 0.90 & 0.90 & 0.90 & 0.90 \\
\hline & RMSE (bar) & 0.01 & 0.02 & 0.03 & 0.04 \\
\hline & $\mathbf{A}_{\mathrm{CC}}$ & 0.95 & 0.95 & 0.94 & 0.94 \\
\hline & CPU Time (s) & 38.12 & 38.58 & 38.25 & 39.12 \\
\hline
\end{tabular}

This decrease in performance is due to the fact that the SIMA is based on the consideration of a future maintenance action that modifies the values of the parameters $T_{h}, P_{h}, P f$ and $T_{e e}$, contrary to the MANFIS-PID1, the SIMA does not integrate the four previous instants of these parameters during the prediction.

Table 4 shows that up to horizon $\mathrm{t}+4$, SIMA presents RMSE values of $2.54\left({ }^{\circ} \mathrm{C}\right)$ and $2.81\left({ }^{\circ} \mathrm{C}\right)$ respectively for the predictions of $T_{\text {let }}$ and $T_{s 2 e t}$. Regarding $T_{h}$, at $\mathrm{t}+4$ days we obtained a RMSE of the order of $0.92\left({ }^{\circ} \mathrm{C}\right)$ which remains satisfactory considering the order of magnitude of the oil temperature. The CPU time values obtained after prediction with SIMA are of the order of 40 seconds.

\subsection{MANFIS-PID1 system performance}

Table 5 shows the parameters $K p, K i$ and $K d$ of the MANFISPID1 system determined by solving Eq. (23). Since the parameter $K p$ are zero, the controllers are of the PD type.

Table 5. Combinations of $K p, K i$ and $K d$ parameters for the MANFIS-PID1 system

\begin{tabular}{c|c|c|c|c|c}
\hline \multirow{2}{*}{ Parameter } & \multicolumn{5}{|c}{ Significant Parameters of the Degradation } \\
\cline { 2 - 6 } & $T_{\text {let }}$ & $T_{s 2 e t}$ & $T_{h}$ & $P_{h}$ & $P f$ \\
\hline$K_{p}$ & 0.90 & 0.90 & 0.81 & 1.00 & -0.21 \\
\hline$K_{i}$ & 0 & 0 & 0 & 0 & 0 \\
\hline$k_{d}$ & 0.69 & 0.59 & 0.07 & 0.59 & -0.21 \\
\hline
\end{tabular}

Figure 7 shows the predictions for $T_{\text {let }}$ at $\mathrm{t}+4$ days horizon of prediction. At the level of data 22, we notice a peak in the real temperature value. This peak is unknown to the MANFISPID model. This means that we observe that the predicted value at data 22 is considerably lower than the real value. The observed prediction error is used in the calculation of the PID controller command for the prediction of data 23 .

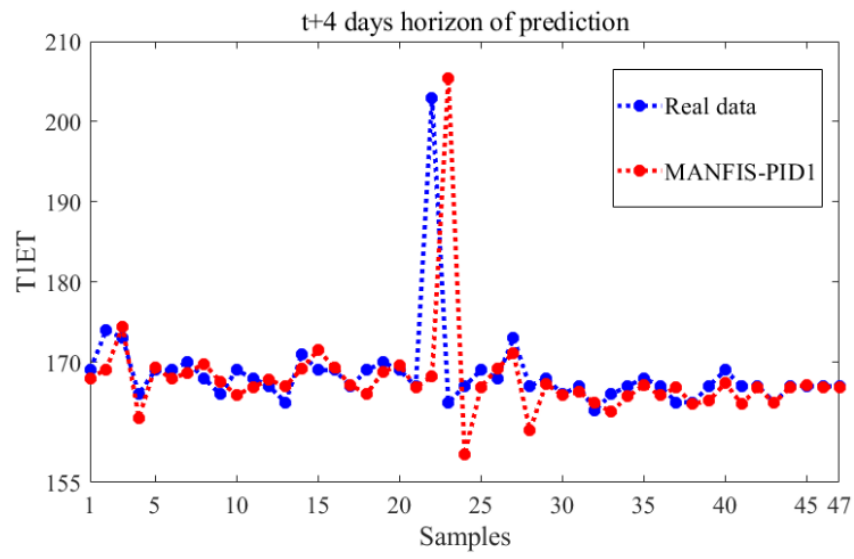

Figure 7 . Results of the prediction of $T_{\text {let }}$ via the MANFISPID1

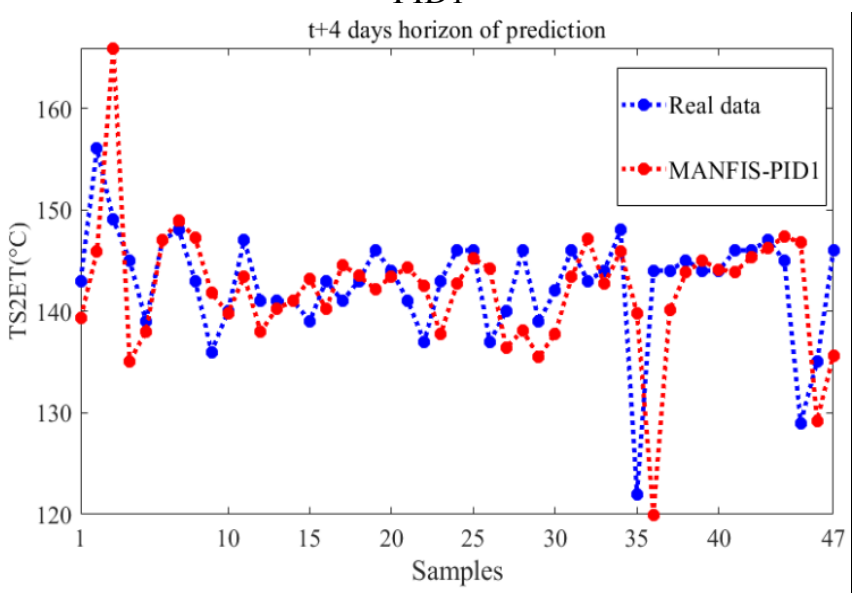

Figure 8 . Results of the prediction of $T_{s 2 e t}$ via the MANFISPID1 
Figure 8 shows the predictions of the $T_{s 2 e t}$ parameter made by the MANFIS-PID1 system. The difference between the real data and the predicted data is around 2.

Figure 9 shows the predictions of $T h$ at horizon $\mathrm{t}+4$. We note that the differences between the predicted and actual data are on the order of $1\left({ }^{\circ} \mathrm{C}\right)$.

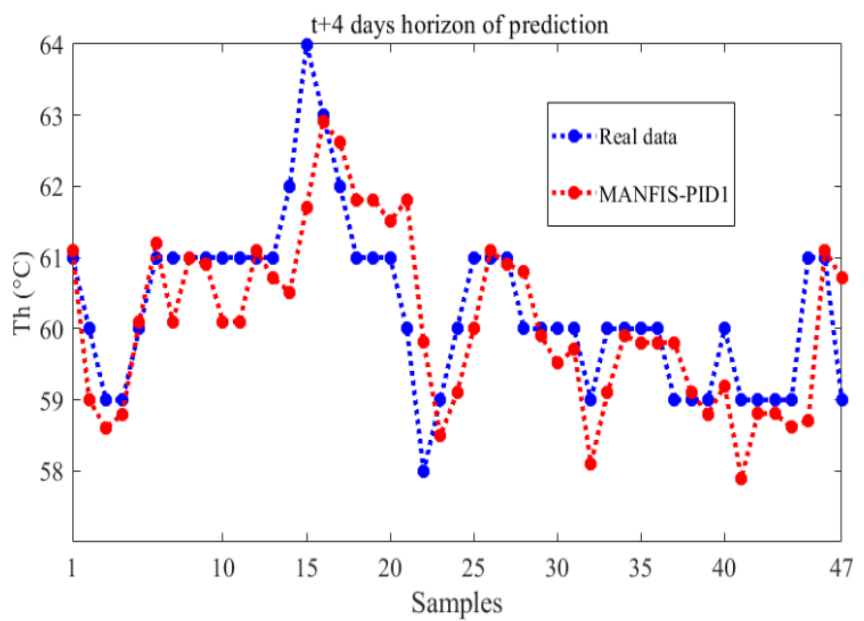

Figure 9. Results of $\mathrm{T}_{\mathrm{h}}$ prediction via MANFIS-PID1

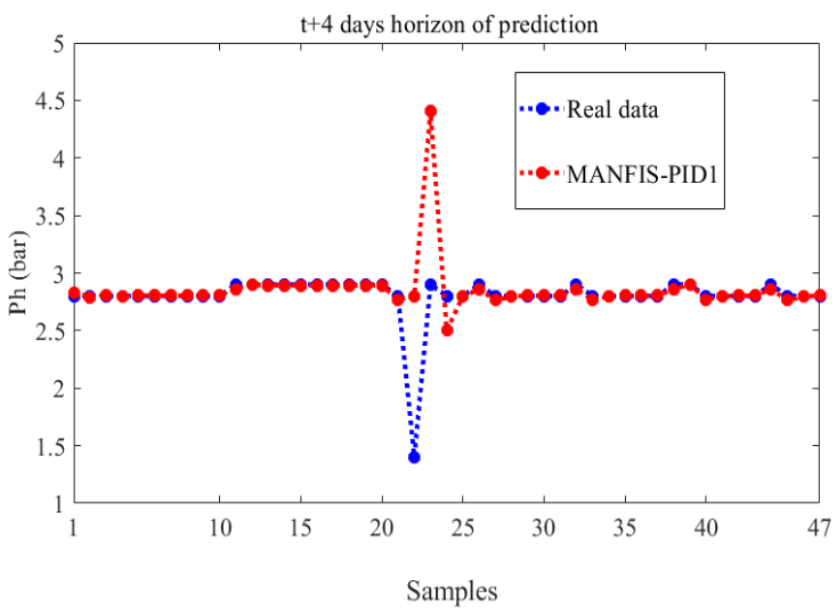

Figure 10. Results of the prediction of $P_{h}$ via the MANFISPID1

Figure 10 and Figure 11 shows that for the prediction of $P_{h}$, the curve of the data predicted by the MANFIS-PID1 system is quite similar to that of the real data.

Within the framework of the prediction of $P_{h}$ the implemented PID controller delivers a command calculated from the absolute value of the error between the predicted values and the real values. This explains the observation of a peak in the opposite direction.

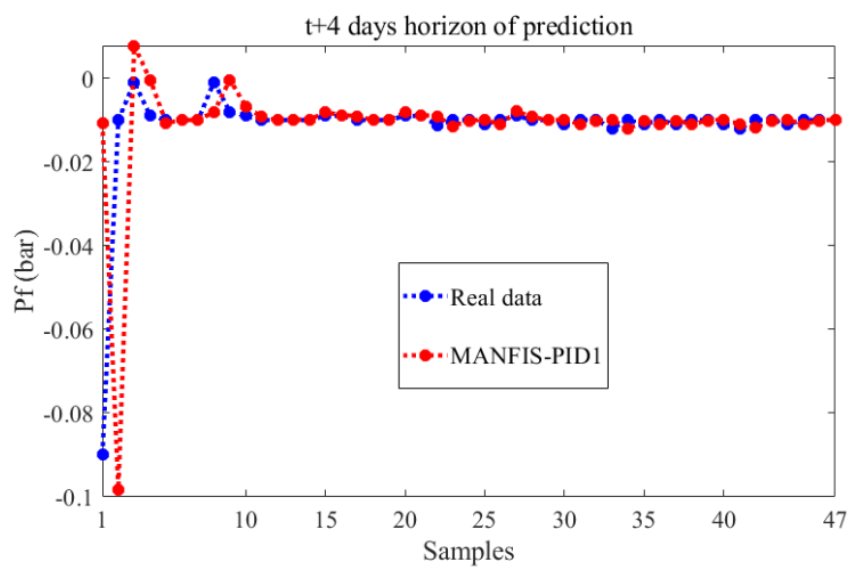

Figure 11. Results of $P f$ prediction via MANFIS-PID1

\subsection{Performances of SIMA}

Table 6 shows the values of the parameters $\mathrm{Kp}, \mathrm{Ki}$ and $\mathrm{Kd}$ of the MANFIS-PID2 and MANFIS-PID3 systems of SIMA. We also notice that the optimal Ki parameters of MANFISPID2 and MANFIS-PID3 systems are zero. We have PD type controllers.

Table 6. Combinations of $K p, K i$ and $K d$ parameters for MANFIS-PID2 and MANFIS-PID3 systems

\begin{tabular}{|c|c|c|c|c|c|c|}
\hline & \multirow[t]{2}{*}{$\begin{array}{c}\text { PID } \\
\text { Parameter }\end{array}$} & \multicolumn{5}{|c|}{$\begin{array}{c}\text { Significant Parameters of the } \\
\text { Degradation }\end{array}$} \\
\hline & & $T_{\text {let }}$ & $T_{s 2 e t}$ & $T_{h}$ & $P_{h}$ & $P f$ \\
\hline \multirow{3}{*}{$\begin{array}{l}\text { MANFIS- } \\
\text { PID2 }\end{array}$} & $\boldsymbol{K}_{p}$ & 0.90 & 0.91 & 0.82 & 0.80 & -0.7 \\
\hline & $\boldsymbol{K}_{i}$ & 0 & 0 & 0 & 0 & 0 \\
\hline & $\boldsymbol{K}_{d}$ & 0.59 & 0.41 & 0.11 & 0.44 & -0.4 \\
\hline \multirow{3}{*}{$\begin{array}{l}\text { MANFIS- } \\
\text { PID3 }\end{array}$} & $\boldsymbol{K}_{p}$ & 1.10 & 1.11 & 1.00 & 0.92 & -0.9 \\
\hline & $\boldsymbol{K}_{i}$ & 0 & 0 & 0 & 0 & 0 \\
\hline & $\boldsymbol{K}_{\boldsymbol{d}}$ & 0.45 & 0.50 & 0.19 & 0.45 & -0.1 \\
\hline
\end{tabular}

The comparative analysis of the curves of the real data and the data predicted by SIMA is presented by Figure 12, Figure 13, Figure 14 Figure 15 and Figure 16. The real data set is the same as the one used for the MANFIS-PID1 performance analysis.

Despite the fact that in SIMA, the MANFIS-PID2 and MANFIS-PID3 systems do not take into account the four previous instants to predict the next instant, because of the FMA, the curves of the predicted data remain close to the real data.

Figure 12 and Figure 13 show respectively the predictions of the parameters $T_{\text {let }}$ and $T_{s 2 e t}$ at the horizon $\mathrm{t}+4$ days, after a FMA which modified essentially the parameters $T_{e e}, T_{h}, P_{h}$ and $P f$. The analysis of these figures shows that SIMA makes it possible to predict the evolution of the fouling of the air coolers after a FMA which corrected only the fouling of the 
oil cooler and the clogging of the air and oil filters. The difference between the predicted data and the data remains generally close to $5^{\circ} \mathrm{C}$. SIMA shows the same behavior in front of the peaks of values.

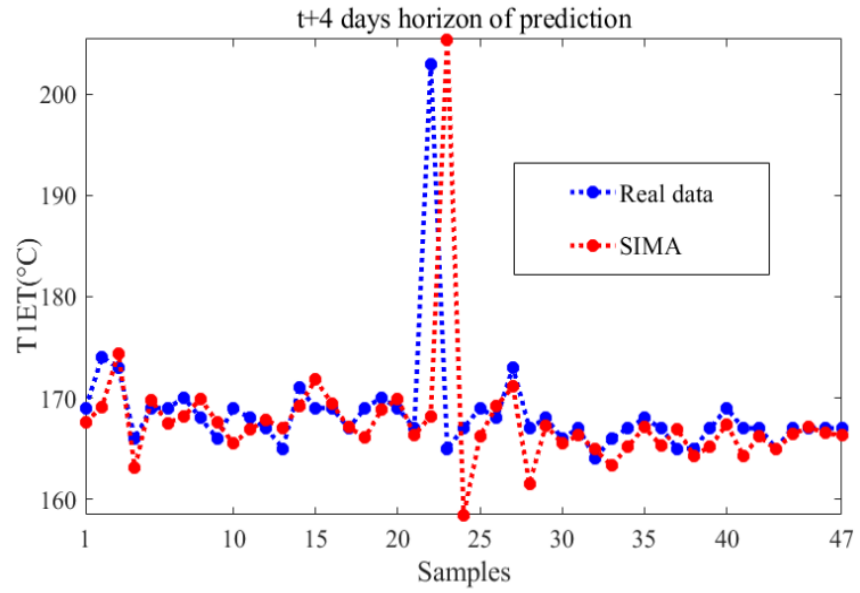

Figure 12. Results of the prediction of $T_{\text {let }}$ via the SIMA

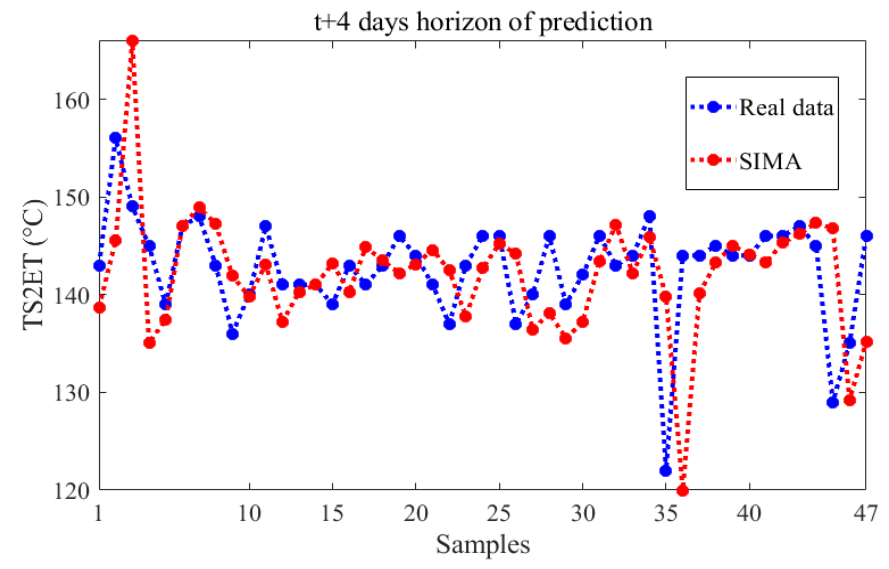

Figure 13. $T_{s 2 e t}$ prediction results via the SIMA

Figure 14 shows the predictions of $T_{h}$ after an FMA that corrects the oil cooler fouling without correcting the air cooler fouling.

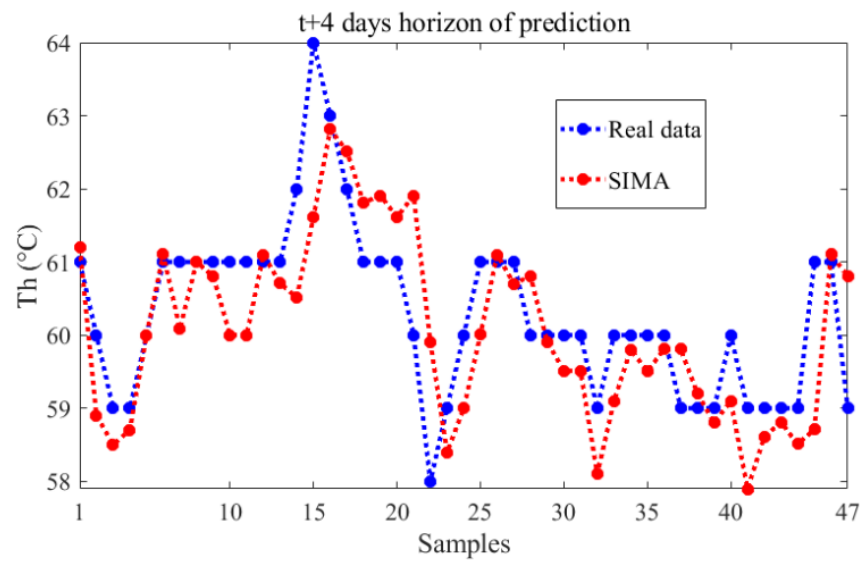

Figure 14. Results of the prediction of $T_{h}$ via the SIMA
The difference between the real data and the predicted data remains close to $1^{\circ} \mathrm{C}$.

Figure 15 shows the predictions of $P_{h}$ by SIMA at time $\mathrm{t}+4$. The observation of a peak in the opposite direction is justified by the fact that the PID controllers deliver commands calculated from the absolute values of the error.

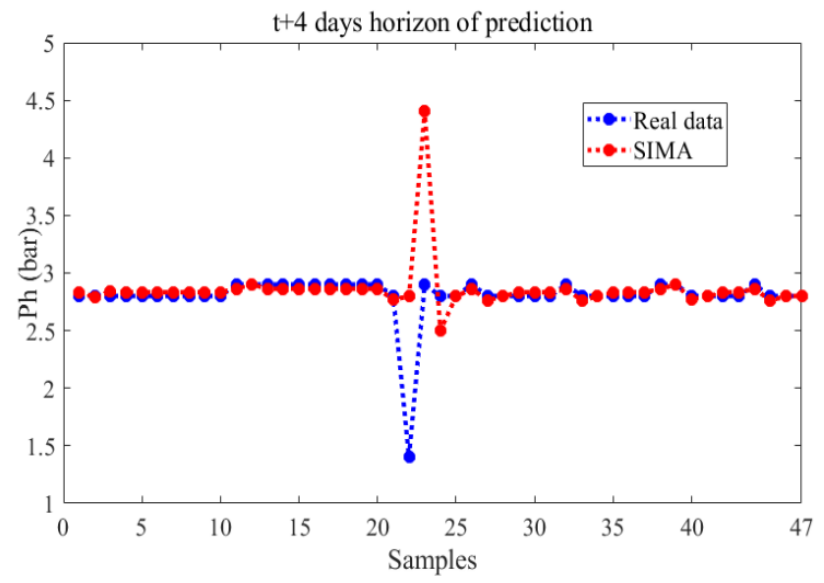

Figure 15. Results of the prediction of $P_{h}$ via the SIMA

Figure 16 shows that the curve of values predicted by SIMA remains close to the curve of real values.

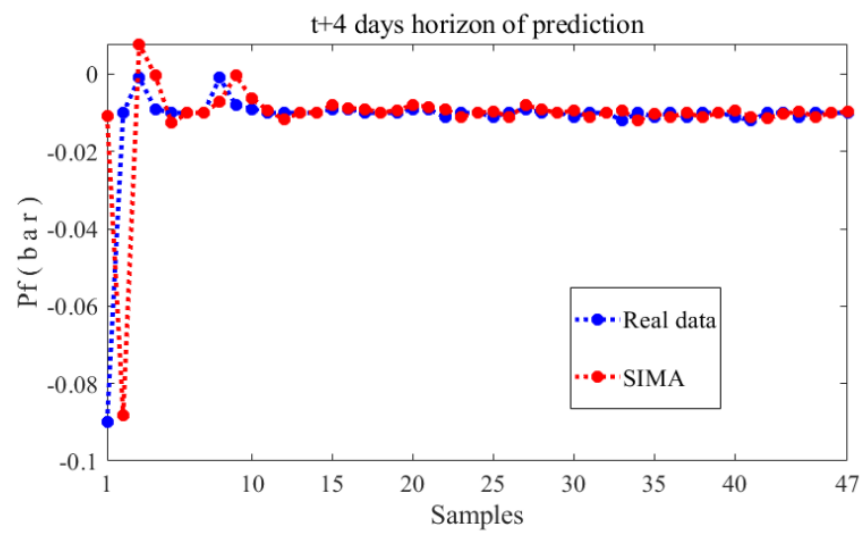

Figure 16. Results of the Pf prediction via the SIMA

\subsection{Proposed prognosis framework for integration of futures maintenance actions}

Figure 17 illustrates the general analytical framework of predictive maintenance presented by Wang, Zhang, Duan, and Gao, (2017). The aim of predictive maintenance is to provide decision support for maintenance scheduling by diagnosing the defects and predicting the remaining service life of equipment. A prognosis framework typically incorporates data acquisition, data manipulation (feature extraction and feature selection), fault detection, fault diagnosis, prognosis and decision support in sequential order (Zhang, Lin, Liu, Zhang, Yan, and Wei, 2019). 


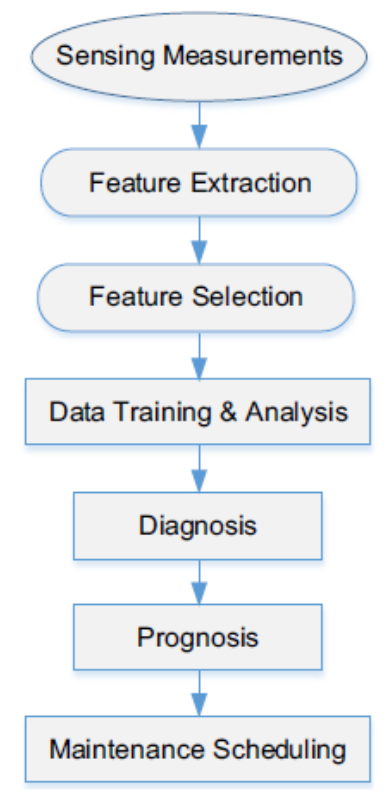

Figure 17. Analytical framework for predictive maintenance (Wang et al., 2017)

Based on the analysis of the prognostic framework proposed in the literature, we propose in Figure 18, a new prognostic framework for the integration of future maintenance actions with prediction.

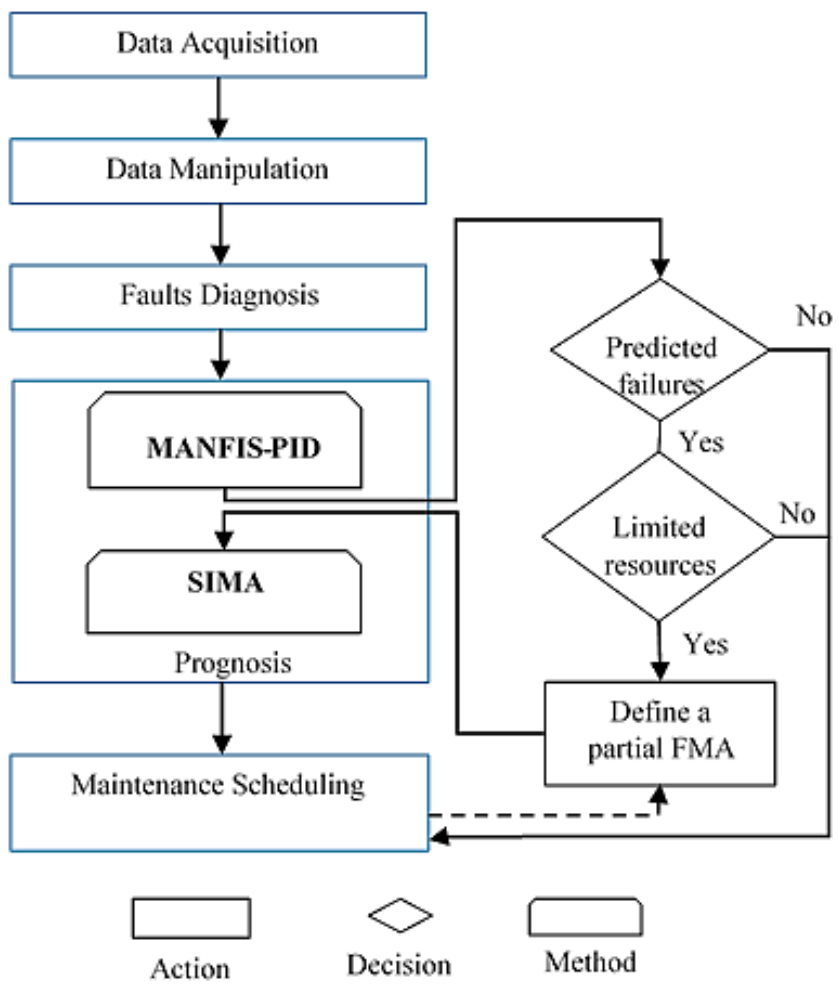

Figure 18. Implementation process of the proposed prognosis framework
In the proposed prognosis framework, after the faults diagnosis, the prognosis starts by implementing the MANFIS-PID method for a first prediction. If MANFIS-PID predicts the occurrence of failures, and the resources (human, material...) of the company are limited to completely remedy the failure, the maintenance department defines a scheduled FMA to be integrated into the prediction. This FMA defined from the maintenance schedule is partial because it is implemented while waiting for the necessary means to be available for a definitive maintenance action. The FMA thus defined will initialize certain parameters for a new prediction, this time carried out by the SIMA. The prognostic action is completed after the implementation of the SIMA which allows to predict how long the equipment could still work if a partial maintenance action is executed. The process continues with maintenance scheduling.

\section{CONCLUSION}

In this paper, we propose a model for integrating future maintenance actions with the prediction of coolers fouling and filter clogging phenomena of the ATLAS COPCO compressor. We start from the combined analysis of the failure modes and the significant parameters of the compressor degradation, to establish the interdependence relations between the parameters whose evolution is characteristic of the phenomena of cooler fouling and filter clogging.

The combination of Proportional Integral Derivative controllers whose parameters remain constant, with a NeuroFuzzy system has allowed to form a MANFIS-PID type system. It allowed to successfully predict the evolution of the compressor parameters in the short term. The analysis of the first results obtained already shows that the control of the prediction error, and the taking into account of the four previous instants allow to obtain good precision and satisfactory values of the error without increasing the complexity of the algorithm.

In a second step, we assume that the MANFIS-PID system has predicts the simultaneous occurrence in the near future of fouling of air and oil coolers and clogging of air and oil filters. In this eventuality we propose the SIMA (made up of two MANFIS-PID type systems), which allows to integrate a partial Future Maintenance Action (FMA) to the prediction of the compressor failures. In the case of our study we simulated the integration of a partial FMA that corrects the oil cooler fouling and air and oil filter clogging phenomena, without correcting the air cooler fouling phenomenon. The new system of integrating Future Maintenance Actions (FMA) into the prediction offers good performance with low computation time.

We have proposed a prediction model to integrate a partial FMA with the prediction of the phenomena of cooler fouling and filter clogging. However, the prediction of wear phenomena of mechanical components from vibration and 
pressure data seems relevant to us and will be the subject of our future work.

\section{ACKNOWLEDGEMENT}

We would like to thank the SOCAVER Company from Douala-Cameroon which allowed us to stay in its premises during the completion of this work.

\section{REFERENCES}

Abdulshahed, A., Longstaff, A. P., Fletcher, S., and Myers, A. (2013). Comparative study of ANN and ANFIS prediction models for thermal error compensation on CNC machine tools. In Lamdamap 10th International Conference (pp. 79-89).

Adeline, R. Gouriveau, R. and Zerhouni, N. (2008). Pronostic de défaillances: Maîtrise de l'erreur de prédiction. LISMMA, CRAN, ENSTIB. 7ème Conférence Internatio-nale de Mobilisation et Simulation, MOSIM'08. Paris, France. 1 (sur CD ROM), 10 p. $<$ hal00270725>.

Atlas Copco, (2014). Instruction manual, N ${ }^{\circ} 29221815$ 03, consulted on December 08, 2017 on the site www.atlascopco.com.

Atsalakis, G. S., Atsalaki, I. G., and Zopounidis, C. (2018). Forecasting the success of a new tourism service by a neuro-fuzzy technique. European Journal of Operational Research, 268(2), 716-727.

Auand, S. M. and Priyanka C. P. (2016). A Comparative Analysis of Fault prediction and Speed Control of Induction Motor using ANN and ANFIS, International Advanced Research Journal in Science, Engineering and Technology. National Conference on Emerging Trends in Engineering and Technology (NCETET'16). Lourdes Matha College of Science \& Technology, Thiruvananthapuram. Vol. 3, Special Issue 3.

Bayatzadeh, F. Z., Ghadimi F. and Fattahi H. (2016). Use of artificial intelligence techniques to predict distribution of heavy metals in groundwater of Lakan lead-zinc mine in Iran. Journal of Mining \& Environment, Vol.8, No.1, 3548. DOI: 10.22044/jme. 592, 2017.

Bouzidi, Z., Terrissa, L. S., Zerhouni, N. and Ayad S. (2020). QoS of cloud prognostic system: application to aircraft engines fleet. European J. Industrial Engineering, Vol. 14, No. 1, https://doi.org/10.1504/EJIE.2020.105080.

Cao, Y., Babanezhad, M., Rezakazemi, M., and Shirazian, S. (2020). Prediction of fluid pattern in a shear flow on intelligent neural nodes using ANFIS and LBM. Neural Computing and Applications, 32(17), 13313-13321.

Chai, T. \& Draxler, R. R. (2014). Rootmean square error (RMSE) ormean absolute error (MAE) - arguments against avoiding RMSE in the literature. Geosci Model Dev, 7(3), 1247-1250. https://doi.org/10.5194/gmd-7$\underline{1247-2014}$.
Daher,A., Hoblos, G., Khalil, and M., Chetouani, M. (2020). New prognosis approach for preventive and predictive maintenance - Application to a distillation column. Chemical Engineering Research and Design, Volume 153, Pages 162-174, ISSN 0263-8762, https://doi.org/10.1016/j.cherd.2019.10.029

Dragomir, O. E. Dragomir, F. Stefan, V. and Minca, E. (2015). Adaptive neuro-fuzzy inference systems as a strategy for predicting and controling the energy produced from re-newable sources. Energies, 8, pp. 13047-13061. [Google Scholar] [CrossRef].

Dragomir, O. E. V. (2008). Contribution to the Prognosis of Failures by Neuro-Fuzzy Network: Control of the Prediction Error. Automatic/Robotics. University of Franche Comté, France. French. <tel-00362509>.

El Adraoui, I., Gziri, H., \& Mousrij, A. (2020a). Diagnostic and Prognostic Model for a System for Guiding a Microwave Oven Subjected to Degradation. International Journal of Advanced Science and Technology, Vol 29 - No. (3), pp. 14503 14519.http://sersc.org/journals/index.php/IJAST/article/ view/31935.

El Adraoui, I., Gziri, H., and Mousrij, A. (2020b). Prognosis of a Degradable Hydraulic System: Application on a Centrifugal Pump. International Journal of Prognostics and Health Management, ISSN 2153-2648.

Elasha, F., Shanbr, S., Li, X., and Mba, D. (2019). Prognosis of a Wind Turbine Gearbox Bearing Using Supervised Machine Learning. Sensors, 19, 3092. https://doi.org/10.3390/s19143092

Elbaz, K., Shen, S. L., Sun, W. J., Yin, Z. Y., and Zhou, A. (2020). Prediction model of shield performance during tunneling via incorporating improved particle swarm optimization into ANFIS. IEEE Access, 8, 39659-39671.

Gouriveau, R., \& Medjaher, K. (2011). Prognostics. Part: Industrial Prognostic-An Overview. Maintenance Modelling and Applications. 10-30.

Hanachi, H., Jie, L. I. U., and Mechefske, C. (2018). Multimode diagnosis of a gas turbine engine using an adaptive neuro-fuzzy system. Chinese Journal of Aeronautics, 31(1), 1-9.

Hanachi, H., Liu, J., Banerjee, A., and Chen, Y. (2016). Prediction of Compressor Fouling Rate Under Time Varying Operating Conditions. Proceedings of the ASME Turbo Expo 2016: Turbomachinery Technical Conference and Exposition. Volume 6: Ceramics; Controls, Diagnostics and Instrumentation; Education; Manufacturing Materials and Metallurgy. Seoul, South Korea. V006T05A003. ASME. https://doi.org/10.1115/GT2016-56242.

Hyndman, R. J., \& Koehler, A. B. (2006). Another look at measures of forecast accuracy. Int J Forecast, 22(4), 679-688. https://doi.org/10.1016/j.ijforecast.2006.03.001. 
Jang, J. S. R. \& Sun, C.T. (1995). Neuro-fuzzy model-ing and control. Proceedings of the IEEE 83 (3), pp. 378406.

Jang, J. S. R. (1993). ANFIS: Adaptive-network-based fuzzy inference systems. IEEE Trans. Syst., Man, and Cy-bern, 23, pp. 665-685.

Jang, J. S. R., Suni, C. T., and Mizutani, E. (1997). Neurofuzzy and soft computing: a computational approach to learning and machine intelligence. New York: Prentice Hall.

Jeong, Y., Son, S., Cho, S.K., Baik, S., and Lee, J.I. (2020). Evaluation of supercritical $\mathrm{CO} 2$ compressor off-design performance prediction methods, Energy, Volume 213, 119071, ISSN 0360-5442, https://doi.org/10.1016/j.energy.2020.119071.

Jombo, G., Pecinka, J., Sampath, S., and Mba, D. (2018). "Influence of Fouling on Compressor Dynamics: Experimental and Modeling Approach." ASME. J. Eng. Gas Turbines Power. 140(3): 032603. https://doi.org/10.1115/1.4037913

Kar S., Das S., and Ghosh P. K., (2014), Applications of neuro fuzzy systems: A brief review and future outline, Applied Soft Computing, Volume 15, Pages 243-259, ISSN 1568-4946, https://doi.org/10.1016/j.asoc.2013.10.014.

Karahoca A., Karahoca D. (2011). GSM churn management by using fuzzy c-means clustering and adaptive neuro fuzzy inference system, Expert Systems with Applications, Volume 38, Issue 3, Pages 1814-1822, ISSN0957-4174, https://doi.org/10.1016/j.eswa.2010.07.110.

Kordestani, M., Samadi, M. F., and Saif, M. (2020). A New Hybrid Fault Prognosis Method for MFS Systems Based on Distributed Neural Networks and Recursive Bayesian Algorithm. IEEE Systems Journal, vol. 14, no. 4, pp. 5407-5416, doi: 10.1109/JSYST.2020.2986162.

Lemaitre González, E. (2019). Definition of a prognosis function for multi-component technical systems taking into account the uncertainties from the prognoses of their components (Doctoral dissertation).

Lobo, M. \& Guntur, R. D. (2018). Spearman's rank correlation analysis on public perception toward health partnership projects between Indonesia and Australia in East Nusa Tenggara Province, J. Phys.: Conf. Ser. 1116 022020 .

Martínez-Soto R., Castillo O., and Castro J.R. (2014) Genetic Algorithm Optimization for Type-2 Non-singleton Fuzzy Logic Controllers. In: Castillo O., Melin P., Pedrycz W., Kacprzyk J. (eds) Recent Advances on Hybrid Approaches for Designing Intelligent Systems. Studies in Computational Intelligence, vol 547. Springer, Cham. https://doi.org/10.1007/978-3-319-05170-3_1.

Motahari-Nezhad, M. \& Jafari, S.M. (2020). ANFIS system for prognosis of dynamometer high-speed ball bearing based on frequency domain acoustic emission signals.
Measurement,

166 ,

108154 https://doi.org/10.1016/j.measurement.2020.108154.

Naphon, P., Arisariyawong, T., Wiriyasart, S., \& Srichat, A. (2020). ANFIS for analysis friction factor and Nusselt number of pulsating nanofluids flow in the fluted tube under magnetic field. Case Studies in Thermal Engineering, 18, 100605.

Perstedt, I. \& Tuhkanen, S. (2017). Industrial transformation of the compressor industry.

Sammouri, W. (2014). Data mining of temporal sequences for the prediction of infrequent failure events: application on oating train data for predictive maintenance. Signal and Image processing. Université Paris-Est, English. <NNT: 2014PEST1041>. <tel01133709>.

Soualhi, A., Medjaher, K., Celrc, G., and Razik, H. (2020). Prediction of bearing failures by the analysis of the time series. Mechanical Systems and Signal Processing, Volume 139, 106607, ISSN 0888-3270, https://doi.org/10.1016/j.ymssp.2019.106607.

Soualhi, A., Razik, H., and Clerc, G. (2019). Data Driven Methods for the Prediction of Failures. IEEE 12th International Symposium on Diagnostics for Electrical Machines, Power Electronics and Drives (SDEMPED), pp. 474-480, doi: 10.1109/DEMPED.2019.8864877.

Soualhi, M., Nguyen, K.T.P., Soualhi, A., Medjaher, K., and Hemsas, K.E. (2019). Health Monitoring of Bearing and Gear Faults by Using a New Health Indicator Extracted From Current Signals. Measurement, Volume 141, Pages 37-51, ISSN 0263-2241, doi: https://doi.org/10.1016/j.measurement.2019.03.065

Sparthan, T., Nzie, W., Soh Fotsing, B., Beda, T. and Garro, O. (2020). A Valorized Scheme for Failure

Suganya, R., \& Shanthi, R. (2012). Fuzzy c-means algorithma review. International Journal of Scientific and Research Publications, 2(11), 1.

Syahputra, R. (2016). Application of neuro-fuzzy method for prediction of vehicle fuel consumption. Journal of Theoretical and Applied Information Technology (JATIT), 86(1), pp. 138-149.

Tjahe, A. V., Mtopi Fotso, B. E., Djanna, F. K., and Fogue M. (2017a). Proposition of multi-ANFIS Architecture Mounted in Series for the Multi-Parameters Prediction. In-ternational Journal of Engineering Research \& Technology (IJERT), ISSN: 2278-0181, Vol. 6, Issue 07, pp. 646-652.

Tjahe, A. V., Mtopi Fotso, B. E., Djanna, F. K., and Fogue M. (2017b). Proposition of a MANFIS-PID Hybrid System for the Prediction of Several Interdependent Parameters. International Journal of Engineering Research \& Technolo-gy (IJERT), ISSN: 2278-0181, Vol. 6, Issue 07, p. 653-661.

Wang, H., Hong, R., Chen, J., and Tang, M. (2015). Intelligent health evaluation method of slewing bearing adopting multiple types of signals from monitoring system. International Journal of Engineering (IJE), 
TRANSACTIONS A: Basics Vol. 28, No. 4, pp. 573582.

Wang, J., Zhang, L., Duan, L., and Gao, R., X. (2017). A new paradigm of cloud-based predictive maintenance for intelligent manufacturing. Journal of Intelligent Manufacturing, 28(5), 1125-1137.

Wong Y. J., Arumugasamy S. K., Chung C. H., Selvarajoo A., and Sethu V. (2020). Comparative study of artificial neural network (ANN), adaptive neuro-fuzzy inference system (ANFIS) and multiple linear regression (MLR) for modeling of $\mathrm{Cu}$ (II) adsorption from aqueous solution using biochar derived from rambutan (Nephelium lappaceum) peel. Springer Nature Switzerland AG, https://doi.org/10.1007/s10661-020-08268-4.

Zagorowska, M., Spüntrup, F. S., Ditlefsen, A. M., Imsland, L., Lunde, E., and Thornhill, N. F. (2020). Adaptive detection and prediction of performance degradation in off-shore turbomachinery. Applied Energy, 268, 114934.

Zemouri R. (2003), Recurrent Radial Basis Function network for Time-Series Prediction, Eng Appl of Artif Intell, 16, 453-463.

Zemouri R., Gouriveau R. and Patic P. C. (2010). Combining a recurrent neural network and a PID controller for prognostic purpose: A way to improve the accuracy of predictions, Wseas Transactions On Systems And Control, 5, 353-371.

Zhang, L., Lin, J., Liu, B., Zhang, Z., Yan, X., \& Wei, M. (2019). A review on deep learning applications in prognostics and health management. IEEE Access, 7, 162415-162438.

Zhuang, X., Yu, T., Sun, Z., and Song, K. (2021). Wear prediction of a mechanism with multiple joints based on ANFIS. Engineering Failure Analysis, 119, 104958.

Zid, K., Ahmed, M.B. and Turki, M. (2018) Modeling of Flank Wear Using ANFIS. Proceedings of the 4th International Conference on Engineering \& MIS, Istanbul, Article No. 47. 